\begin{tabular}{|c|c|c|c|c|}
\hline $\begin{array}{ll}1 & \begin{array}{l}\text { Up in the air } \\
\text { Bioweapons treaty } \\
\text { remains hampered } \\
\text { by divisions } \\
\text { p865 }\end{array}\end{array}$ & 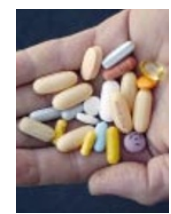 & $\begin{array}{l}\text { Resistance path } \\
\text { Strict drug guidelines } \\
\text { not needed to halt } \\
\text { HIV mutation } \\
\text { p866 }\end{array}$ & $\begin{array}{l}\text { Heating up } \\
\text { Climate modellers } \\
\text { count the cost } \\
\text { of failure } \\
\text { p867 }\end{array}$ & $\begin{array}{l}\text { Publicity probe } \\
\text { Controversies put } \\
\text { scientific results } \\
\text { under scrutiny } \\
\text { p868 }\end{array}$ \\
\hline
\end{tabular}

\title{
NASA braced for culture shock as Columbia inquiry reaches verdict
}

Tony Reichhardt, Washington

Six months after the loss of the space shuttle Columbia and its crew, the panel charged with investigating the accident is set to reveal its findings.

The report from the Columbia Accident Investigation Board (CAIB), due to be published on 26 August, is expected to be highly critical of the US space agency - and its implications for the future of manned space flight could be profound.

"There's no doubt that the report will be important," says Howard McCurdy, a space-policy expert at the American University in Washington DC. "The question is whether it will be influential, or whether everybody will graciously receive it, forget about it and go back to flight."

Columbia disintegrated on 1 February as it attempted to re-enter Earth's atmosphere. Uncovering the cause of the accident has been relatively straightforward, if labour-intensive. CAIB members found their 'smoking gun' last month following a lab test in which a chunk of insulating foam, shot from a gun at 800 kilometres per hour, blew a gaping hole in a section of the shuttle's wing.

The test confirmed a 'working scenario' that the 13-member board and NASA investigators had been building for months. Columbia's break-up was caused by just such an impact, sustained when a piece of insulating foam broke away from a fuel tank during take-off. The resulting hole allowed superheated gases to enter and fatally damage the wing during re-entry.

But other kinds of smoking gun have been harder to come by. Despite the news media's focus on e-mails sent by low-level NASA engineers apparently warning of impending disaster before Columbia's return, these turned out to be hypothetical scenarios rather than deeply felt concerns.

What the CAIB investigation has revealed
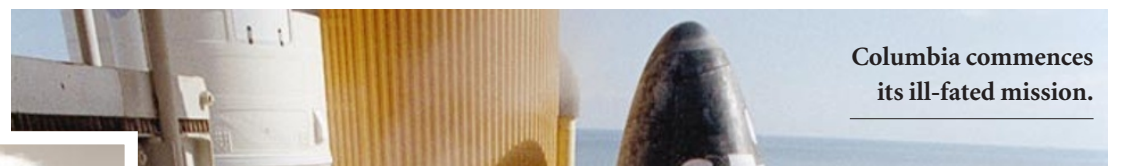

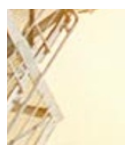

is more subtle, and perhaps more troubling a culture at NASA that left staff staring a fatal problem in the face without noticing. Shuttle engineers had become complacent over the years about insulation foam striking the vehicle, in part because they had never analysed the risk in detail. The antiquated software used to assess the effects of the foam impact on Columbia didn't even consider damage to material on the wing's leading edge, where the foam actually hit. Based on this faulty assessment, flight managers accepted that there

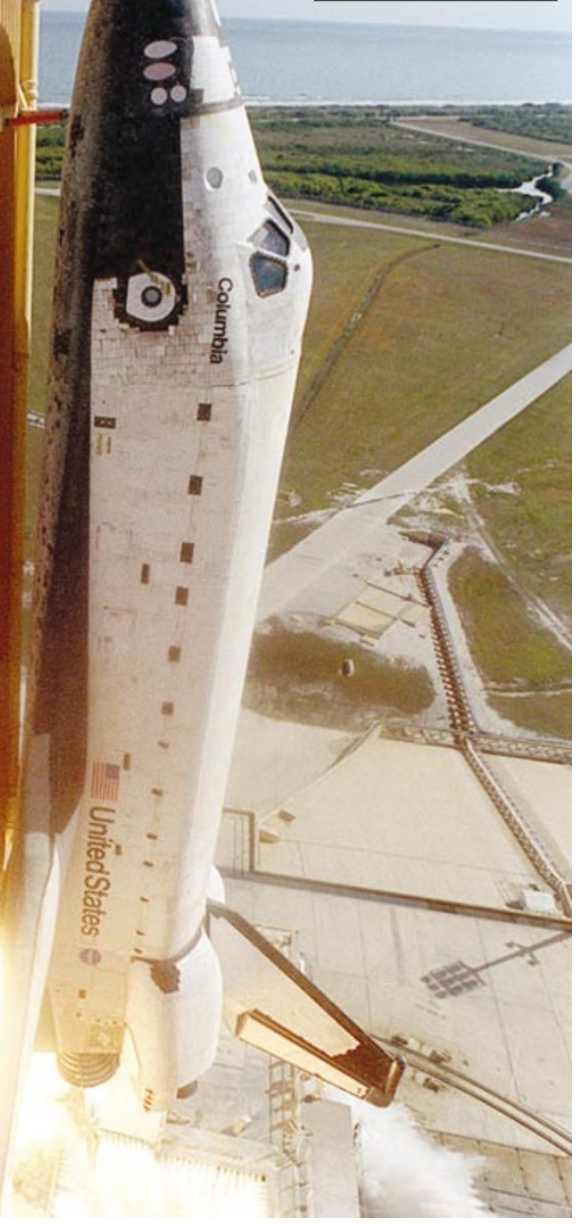

was no danger to Columbia's mission.

With this error in mind, the CAIB is likely to advise NASA to routinely collect far more data on the remaining shuttles' performance and vulnerabilities than it does at present, and to make sure that potential risks come to managers' attention. As Harold Gehman, the retired navy admiral who chairs the CAIB, said during one of the panel's hearings: "You've got to start looking for trouble."

Such a research effort could be expensive. Fixing the shuttles' problems, while designing 
